\title{
Systemic Coaching Supervision: Responding to the Complex Challenges of Our Time
}

\author{
Angela Wright \\ New York, USA \\ Margaret McLean Walsh \\ New York, USA \\ Sarah Tennyson
New York, USA
}

\begin{abstract}
A core challenge for coaching is to develop new paradigms that help coaches, and their clients, navigate today's complex, interconnected and rapidly changing world. This paper explores the evolution of coaching to encompass a broader systemic, developmental perspective in response to ever increasing levels of complexity. We argue that if coaches are to remain relevant and fit for purpose they must engage in ongoing professional development and self-reflection and that this can be enhanced through a systemic, developmental approach to coaching supervision. We introduce and explore the Cycle of Developmental Supervision. Aligning with a Complex Adaptive Systems view of supervision and recognizing the centrality of "self" in coaching outcomes, the Cycle aims to increase reflexivity and breadth of systemic perspective, reflecting an evolution of complexity in thinking, meaning making and coach maturity. Finally, we will discuss implications for practice; suggesting the need for the coaching community to harness its diversity by engaging in a respectful dialogue that is essential to our collective evolution and transformation.
\end{abstract}

Keywords: systemic developmental supervision, reflective practice, use of self, dialogical approach, complex adaptive systems, coach maturity.

In today's complex, interconnected and rapidly changing world, the demands placed on our leaders and organizations have grown exponentially. At the same time, critics have argued that current leadership approaches do not capture the dynamic of organizations operating in today's knowledge driven, competitive and global economy (Lichtenstein et al, 2007), underestimate the complexity of context (Avolio, Walumbwa \& Weber, 2009) and do not

This is an Open Access article distributed under the terms of the Creative Commons Attribution (CC BY) License which permits use, distribution and reproduction in any medium, provided the original work is properly cited. 
recognize that individuals are "embedded in a complex interplay of numerous interacting forces" (Uhl-Bien, Marion \& McKelvey, 2007, p. 302). It has been suggested that leadership needs to fit "the needs of the situation or challenges in which it operates" (Avolio, Walumbwa \& Weber, 2009, p. 430). Moreover, Kegan (1994) has argued that there is a "mismatch" between the expectations we have of our leaders and their level of cognitive development (Lahey, Souvaine, Kegan, Goodman, \& Felix, 1988).

Consistent with these criticisms, this paper argues that for coaches to be fit for purpose in supporting leaders to meet these demands, they too must achieve the 'right fit' between the complex challenges of contemporary society and their own personal and collective capacity to understand, critically consider and integrate multiple perspectives on client issues and the coaching process. This requires coaches to engage in ongoing professional development and selfreflection, which this paper argues is enhanced through coaching supervision. Coaching supervision provides an opportunity for coaches to step back from their work and take a broader view, which is essential to their ongoing effectiveness and transformation.

First, this paper discusses the evolution of coaching to encompass a broader systemic, developmental perspective in response to ever increasing levels of complexity. This paper then outlines the functions of coaching supervision - suggesting that the main purpose of supervision is to help the coach see more than they can currently see, in themselves, others and the systems in which they operate. Next, the Cycle of Developmental Supervision is introduced as a conceptualization of a systemic, developmental approach to supervision. Aligning with a Complex Adaptive Systems view of supervision and recognizing the centrality of "self" in coaching outcomes, the Cycle aims to increase reflexivity and breadth of systemic perspective, reflecting an evolution of complexity in thinking, meaning making and coach maturity. Finally, this paper discusses implications for practice.

\section{Coaching - Towards a Systemic Developmental Perspective}

Early approaches to coaching largely adopted a models-based approach (Clutterbuck \& Megginson, 2011) such as GROW (Whitmore, 1992) that are linear and reductionist (Cavanagh, 2013). Recently, we have seen an increase in more systemic approaches to coaching that have regard to the context in which coaching clients operate (Cavanagh, 2006, 2013; Lawrence \& Moore, 2019). 
There has also been a noticeable shift from performance coaching towards more developmentally focused coaching (Berger, 2006; Bachkirova and Baker, 2018). For the purposes of this paper, and drawing on theories of developmental psychology (e.g. Bachkirova, 2016; Kegan, 1982; Torbert 1991; Cook-Greuter 2004; Wilber, 2000), we describe Developmental Coaching as coaching that is aimed at enhancing a client's ability to meet current and future challenges more effectively as a result of the development of an increasingly complex understanding of self, others and the systems in which they operate (Cavanagh, 2013). Despite critiques of Developmental Coaching around the lack of unifying theory, an evidence base, and its potentially judgmental role, the theories of adult development themselves are respected, researched and intuitively sound (Bachkirova, 2016; Lawrence, 2016).

While relevant in all coaching engagements, there are a number of issues that may be more complex in the practice of Developmental Coaching. For example, the blurring of boundaries between coaching and therapy, the identification of mental health issues, the effects of parallel processing (Bachkirova \& Baker, 2018), challenges around ethical issues and the development of ethical maturity (Lane, 2011) and the stage of development of the coach vis-a-vis the client (Laske, 2007).

Given the increasing focus on the maturation of coaching, developmental and systemic frames, this paper argues that there is an increasingly critical need for coaches to engage in supervision as part of their continuous professional development and reflective practice in order to ensure that they are, and remain, both relevant and fit for purpose.

\section{Supervision - A Systemic Developmental Approach}

The current accepted functions of supervision are described variously as: 1) Qualitative/Normative (ensuring work is professional and ethical); 2) Development/Formative (developing skills, understanding and capacities); and 3) Resourcing/Restorative (providing emotional support) (Hawkins \& Shohet, 2006; Inskipp \& Proctor, 1993). This paper adds a personal developmental dimension consistent with theories of developmental psychology (Bachkirova, 2008) suggesting that, through dialogue in supervision, the coach and the supervisor are able to make visible those things the coach cannot yet see; those things they are blind to; those assumptions they subconsciously hold; those things that are not in the coach's current frame of reference. It is based on the premise that coaches can only bring to supervision that which is currently in their awareness and emphasizes the importance of helping coaches notice what 
they cannot currently see in themselves, their clients, their client organizations and each of the respective systems of which they form part. For example: ethical issues might be identified that the coach may not be aware of as part of the Qualitative/Normative function; it may enhance the coach's capacity to take multiple perspectives as part of the Development/Formative Function; and help the coach see other points of view on what they may perceive as mistakes as part of the Resourcing/Restorative function (Bachkirova, 2008).

The developmental dimension draws on Kegan's (1994) Adult Development Theory (ADT), which focuses on the level of complexity with which a coach makes meaning of the world around them. Consistent with other constructive developmental theories, ADT is concerned with the construction of reality and the development of that construction to more complex levels over time, increasing the coach's systemic breadth of perspective. The theory outlines a mechanism for growth and explains how transformative shifts in meaning making are achieved through "incremental reflection and insight" (Atkins, 2006, p.39). Kegan's (1982, 1994) ADT posits that one of the ways we are able to transform or develop is through the process of moving things in our perception from Subject to Object. Things that are Subject are "those elements of our knowing or organizing that we are identified with, tied to, fused with or embedded in" (Kegan, 1994, p.32). Conversely, things that are Object are "those elements of our knowing that we can reflect on, handle, look at, be responsible for, relate to each other, take control of, internalize, assimilate, or otherwise operate upon" (Kegan, 1994, p.32). A profound shift occurs when we move entire systems from Subject to Object as this represents "a qualitative shift in complexity and meaning making from the order before it" (Berger \& Fitzgerald, 2002, p.35), including it and extending it (Goodman, 2002).

The developmental dimension also draws on Systems Theory, Complexity Science and Systems Intelligence (Cavanagh, 2006, 2013; Hämäläinen \& Saarinen, 2007a, 2007b; Luoma, 2009; Luoma, Hämäläinen, \& Saarinen, 2008; Saarinen \& Hämäläinen, 2004). An understanding of complex systems helps a coach appreciate that they, and their clients, are not objective observers, but a system embedded in a hierarchy of systems (von Bertalanffy, 1986; Saarinen \& Hämäläinen, 2004), and that responses, actions and behaviors within those systems emerge from a continuous interplay of numerous interacting forces (Siegal, 2007). For example, the concept of feedback loops helps us to stop thinking in terms of linear cause and effect and recognize that an organizational system is more than the sum of its parts (Cavanagh, 2006); it is a complex set of interconnected interacting subsystems who "self-organise into characteristic patterns of interaction" (Compernolle, 2007, p.31). 
Consequently, in coaching, it is important to understand the relationships and the interactions between the interconnected subsystems (Ball, Counts, Helfrich, Carol, \& Winn, 1998).

The Developmental dimension emphasizes the importance of a coach increasing their capacity to take multiple systemic perspectives, gain a greater appreciation of the predispositions of their own system (Kemp, 2008), see various stakeholder perspectives and the inherent complexity in the coach/client relationship: "linear, cause and effect thinking in supervision may be highly misleading for both the coach and the supervisor, and hence unhelpful to the client" (Bachkirova, Jackson \& Clutterbuck, 2011, p. 2).

\section{Cycle of Developmental Supervision}

Inspired by Grant's (2012) Cycle of Self-Regulation, the Cycle of Developmental Supervision (Figure 1) is a conceptualization of the process of developmental supervision that aims to generate new insight and awareness in order to increase a coach's capacity to take and integrate multiple perspectives on themselves, others and the systems in which they operate. The Cycle aligns with a Complex Adaptive Systems perspective on coaching (Cavanagh, 2013) that frames the supervision dialogue as a "complex interactive dynamic from which adaptive outcomes emerge" (Uhl-Bien et al., 2007, p. 298). In this way, the supervision dialogue reflects the complexity, unpredictability and emergent nature of the supervision process. The Cycle also acknowledges the centrality of the practitioner's "self" in the achievement of coaching outcomes (Bachkirova, 2016), emphasizing the importance of self-reflection, reflexivity, and the Use of Self as Instrument. The supervision dialogue is seen as a cocreated reflective practice from which insights, perspectives and joint meaning making between the coach and the supervisor emerge.

\section{Overview of the Cycle}

The Cycle starts when the coach brings an Issue to supervision identifying a specific area they would like to Focus on. The coach and the supervisor Explore the issue through the supervision dialogue. During that dialogue, the coach may learn something new, broaden their perspective, shift their thinking. The coach then brings this insight or increased awareness back to their coaching, which impacts the coach themselves, their client, the client organization and potentially the broader coaching community. 


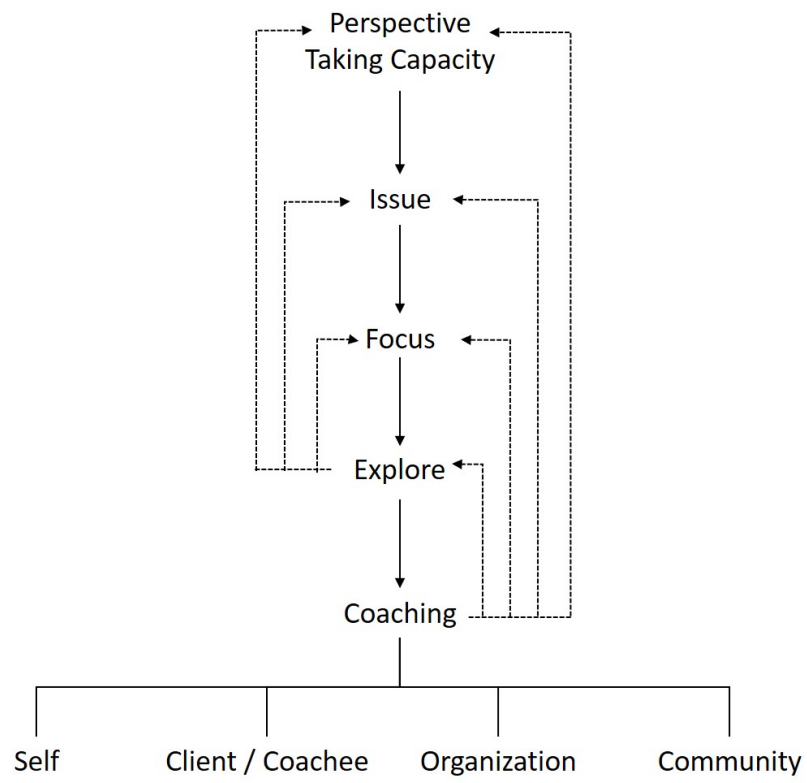

\section{Figure 1: Cycle of Developmental Supervision}

During that exploration, the coach might realize that there is a more important Focus area, or indeed, a more important Issue. They might start to see that which they previously had not seen. For example, they might start to see the systemic aspects of a situation or become more mindful of what they bring to the coaching dynamic. The exploration might bring into awareness the relational aspects of their Issue, or recognize patterns or interconnections. It might take them to the edge of their thinking or beyond their current understandings, increasing their Perspective Taking Capacity. This is reflected in the dotted lines on the left-hand side of Figure 1. Similarly, the coach may take new insights back to their coaching, and through experimentation and reflection, recognize that the Issue requires further exploration during supervision. They may identify other Issues or areas of Focus and/or increase their Perspective Taking Capacity. This is reflected in the dotted lines on the right hand side of Figure 1.

\section{Exploration: A Supervision Dialogue}

The Exploration stage of the Cycle draws on Isaacs' (1999) conceptualization of Dialogue as a "conversation with a center, not sides" ( $\mathrm{p}$. 19). In supervision, the authors see Dialogue as a shared inquiry where the coach and the supervisor think and reflect together. The aim of Dialogue is to reach new understandings, which form a new basis from which to think, act and 
engage. Dialogue asks both coach and supervisor to consider the context or field in which the issues arise, to open themselves to new options and thinking about their underlying assumptions.

The emergent nature of Dialogue prevents it from being reduced to a few simple techniques. In supervision, the supervisor is part of the method and cannot be separated from it. There are no steps they can take that operate independently from how they themselves function. There are, however, four practices that a supervisor may follow that may be conducive to evoking Dialogue (Isaacs, 1999):

1. Listening, which requires a supervisor to develop an inner silence and to listen not only to the words the coach is saying, but also to understand their point of view and the meaning they make.

2. Respecting, which involves a sense of honor that requires the supervisor to look for what is highest and best in the coach.

3. Suspending, which requires a supervisor to suspend their own point of view long enough to understand and value that of another, in all its richness, and to ask themselves the question "what am I missing?"

4. Voicing, which requires a supervisor to reveal what is true for them, regardless of other influences, and to ask themselves, "What needs to be expressed here?" To do this they must be able to listen to their emotional reactions and impulses, to avoid self-censorship and to be courageous.

Engaging in Dialogue requires a commitment to be mindful, that is, to pay attention, on purpose, in a non-judgmental way (Kabat-Zinn, 1990, 1994, $2003,2006,2008)$. Indeed, it has been suggested that mindfulness is critical to developing the ability to hold a perspective on oneself, others and the world (Cavanagh \& Spence, 2012) and in facilitating a Subject-Object shift (Shapiro, Carlson, Astin \& Freedman, 2006). Mindfulness increases the coach's capacity to make connections and recognize patterns across even seemingly disparate situations - opening them up to new options and possibilities for action (Passmore \& Marianetti, 2007). In modeling mindfulness, the supervisor may encourage the openness, curiosity and acceptance that is required in order for a coach to suspend the mental models that prevent them from entering the supervision dialogue with fresh eyes and a free mind. The supervisor may encourage the coach to observe their thoughts as just thoughts, and their emotions simply as reactions to them rather than as reflections of reality 
(Kabat-Zinn, 1994). This, in turn, may result in greater clarity, objectivity and perspective (Kabat-Zinn, 2004).

The supervisor may scaffold and encourage systems thinking and perspective taking through the use of the Seven-Eyed Model (Hawkins \& Shohet, 2006). The Seven-Eyed Model provides a valuable framework for examining the coach's issue from multiple perspectives. The supervisor may also support the coach in developing their reflexivity and their ability to take more complex perspectives through Subject-Object shifts. For example, when a coach is Subject to their beliefs, assumptions and perspectives they are not open to challenge, change or suspension. The supervisor may help the coach develop the ability to step back and make their perspectives the Object of conscious consideration.

During the supervision dialogue it is critical to ensure that developmental challenges are balanced with appropriate support (Berger \& Fitzgerald, 2002; Goodman, 2002; Kegan, 1994) as part of a sensitive and iterative supervision process that validates where the coach is right now (Goodman, 2002). Indeed, without external support new insights can quickly become Subject again (Berger \& Fitzgerald, 2002; Kegan \& Lahey, 2001). Further, attempts to integrate complexity and make Object new and multiple ways of meaning making may stretch the limits of a coach's understanding - their "growing edge" (Berger, 2006) - and "shake up" the way the coach sees the world (Berger \& Fitzgerald, 2002). In this context, it is important for the supervisor to create a holding environment, and a positive emotional space that broadens cognitive and behavioral capacities, expands their view of the world (Ashby, Isen \& Turken, 1999) and builds personal resources for coping, such as social relations and resilience (Fredrickson, 2001; Fredrickson, 2009; Fredrickson \& Branigan, 2005; Fredrickson \& Joiner, 2002). Managing emotions during the supervision dialogue may also enhance the possibility of psychological growth (Passmore, 2007) consistent with the Resourcing/Restorative function of supervision.

\section{Implications for Practice}

\section{Implications for Supervisors}

Supervisors who wish to work with coaches using a systemic developmental approach will need to: 
- Engage in continuous personal and professional development, including educating themselves in systems theories, systemic approaches to supervision, adult development theories and dialogical approaches.

- Reflect on the impact of their own developmental stage on the way they engage in supervision, with whom they work as a supervisor, and the potential limits it places on their supervision. Indeed, one of the biggest challenges may be to develop the capacity to understand their client's perspective while simultaneously holding their own (Berger, 2006).

- Develop their Use of Self as supervisors and model it during the supervision dialogue, including enhancing their capacity to act mindfully and to create a safe holding environment.

- Undertake supervision on their supervision to surface their own implicit assumptions and perspectives, enhance reflexivity, build awareness of the multiple complexities in a system and develop their own perspective taking capacity.

- Develop and articulate their point of view on coaching supervision and specifically the theories that inform their supervision practice so that coaches can make an informed choice when engaging with supervision (Jackson \& Bachkirova, 2019).

- Explicitly contract with coaches around the type of supervision they provide.

\section{Implications for Coaches}

Coaches who wish to remain fit for purpose in the current environment and continue to develop to meet the complexity of future coaching clients and the systemic needs of organizations would benefit from systemic, developmental supervision that:

- Facilitates a more nuanced understanding of complex systems and increases a coach's capacity to integrate complexity and to take multiple perspectives on client issues and the coaching process.

- Actively engages coaches in their own developmental process through the integration of learning, experimentation and reflective practice that takes them to, and beyond, their "growing edge" (Berger, 2006).

- Supports coaches to navigate the boundaries of their own competence, explore ethical issues and to develop their ethical maturity. 
- Helps coaches reflect on their own developmental level and consider its impact on their coaching - what does it enable and what does it constrain?

Coaches need to be able to make an informed choice about the type of supervision and supervisor with which they wish to engage. Since supervision inevitably involves a number of subsystems, it will be important to work with a supervisor who is able to hold and navigate the needs and interactions of the relevant subsystems.

\section{Implications for Educators \& Professional Bodies}

Coach educators and professional bodies delivering coach training and providing accreditation are uniquely positioned to support coaches and coaching practice in being fit for purpose. They can provide greater support for coach development by:

- Adopting more systemic and developmental approaches to coach education and accreditation that facilitate both professional and personal development.

- Moving towards capabilities-based approaches, rather than competence frameworks, that support criticality and reflexivity and are congruent with individual characteristics and values (Bachkirova, 2016).

- Educate organizations using coaching about the importance of developing coach capabilities and the limitations of relying on competencies as a marker of quality assurance.

- Educating coaches as to the functions and benefits of coaching supervision, including the different forms and approaches to supervision.

\section{Implications for Organizations Using Coaching and Building Coaching Cultures} from:

Organizations developing internal coaching capability would benefit

- Adopting more systemic and developmental approaches to coaching that better address the complex environment and the challenges faced by leaders in their organization. 
- Including supervision for both their internal and external coaches as a critical component of their coaching strategy.

- Developing an increased understanding of the nature of the complexities of working in complex systems and the implications for goal setting and predicting coaching outcomes.

\section{Implications for Researchers}

Given the move towards more systemic, developmental approaches to coaching, more theoretically grounded research will be needed in the areas of supervision (Grant, 2012, Hodge, 2016), including more systemic approaches to supervision, group and team coaching (O'Connor, Studholme \& Grant, 2017), as well as longitudinal studies on developmental coaching (Lawrence 2016).

As independent academics, coaching researchers should be encouraged to take the lead in bringing educators, practitioners and professional bodies together to engage in a dialogue around the evolution of coaching, and ethical and philosophical issues relevant to the practice of more systemic and developmental approaches.

\section{Conclusion}

This paper has argued that if coaches are to support leaders and organizations in meeting the demands of our complex, interconnected and rapidly changing world, they too must achieve the 'right fit' between the complex challenges of our contemporary society, and their own personal and collective capacity to understand and integrate multiple perspectives on client issues and the coaching process. We have explored the evolution of coaching to encompass a broader systemic, developmental perspective in response to ever increasing levels of complexity - arguing that engaging in ongoing professional development and self-reflection through a systemic, developmental coaching supervision dialogue will be critical if coaches are to remain relevant and fit for purpose. The Cycle of Developmental Supervision has been introduced and explored. Aligning with a Complex Adaptive Systems view of supervision and recognizing the centrality of "self" in coaching outcomes, the Cycle aims to increase reflexivity and breadth of systemic perspective, reflecting an evolution of complexity in thinking, meaning making and coach maturity. Finally, this paper has discussed implications for practice; suggesting the need for the coaching community to harness its diversity and engage in a respectful dialogue that is essential to our collective evolution and transformation. 


\section{References}

Atkins, P. (2006). Why it takes time to become wise: Conscious and unconscious development processes. Paper presented at the $2^{\text {nd }}$ Meaning Making in Organizational Symposium. Washington, DC.

Ashby, F. G., Isen, A. M., \& Turken, A. U. (1999). A neuropsychological theory of positive affect and its influence on cognition. Psychological Review 106(3), 529-50.

Avolio, B. J., Walumbwa, F. O., \& Weber, T. J. (2009). Leadership: Current theories, research, and future directions. The Annual Review of Psychology 60, 421- 449

Bachkirova, T. (2008). Coaching Supervision: Reflection of changes and challenges. People and Organizations at Work, 16-17.

Bachkirova, T. (2016). The Self of the Coach: Conceptualization, Issues, and Opportunities for Practitioner Development. The Consulting Psychology Journal: Practice and Research 68(2), 143.

Bachkirova, T., \& Baker, S. (2018). Revisiting the issue of boundaries between coaching and counselling. In S. Palmer, \& A. Whybrow, A. (Eds.). (2018). Handbook of coaching psychology: A guide for practitioners. Abingdon: Routledge.

Bachkirova, T., Jackson, P. \& Clutterbuck, D. (2011). Coaching and mentoring supervision: Theory and practice. Maidenhead: McGraw-Hill Education

Ball, J. R., Counts, D., Helfrich, J. M., Carol, V., \& Winn, C. (1998). An organization-wide approach for an effective communication system. Journal of Nursing Administration, 28(3), 28-34.

Berger, J. G. (2006). Adult development theory and executive coaching practice. In D. R. Stober \& A. M. Grant (Eds.), Evidence based coaching handbook. New York: Wiley.

Berger, J. \& Fitzgerald C. (2002) Leadership and Complexity of Mind - The Role of Executive Coaching. In C. Fitzgerald and J. Garvey Berger, Executive Coaching: Practices and Perspectives. Davies-Black Publishing. Palo Alto, CA.

Cavanagh, M. J. (2006). Coaching from a systemic perspective: A complex adaptive conversation. In D. Stober \& A. M. Grant (Eds.), Evidence based coaching handbook. Hoboken, N J: John Wiley \& Sons.

Cavanagh, M. (2013) The coaching engagement in the 21st Century: New paradigms for complex times. In S. David, D. Clutterbuck \& D. Megginson (Eds). Beyond Goals: Effective Strategies for Coaching and Mentoring. London: Gower Publishing. 
Cavanagh, M. \& Spence, G. (2012). Mindfulness in coaching: Philosophy, psychology or just a useful skill? In J. Passmore, D. Peterson, \& T. Freire (Eds.), The Wiley-Blackwell Handbook of Psychology of Coaching and Mentoring, 112-34. London: Wiley-Blackwell.

Clutterbuck, D. \& Megginson, D. (2011). Coach Maturity: An Emerging Concept. In L. Wildflower \& D. Brennan (Eds.), The Handbook of Knowledge-Based Coaching: From theory to practice. Hoboken, N J: John Wiley \& Sons.

Compernolle, T. (2007). Developmental Coaching from a Systems Point of View. In M. F. R Kets de Vries, K. Korotov \& E. Florent-Treacy. Coach and Couch - The Psychology of Making Better Leaders. London: Palgrave Macmillian.

Cook-Greuter, S. R. (2004). Making the case for a developmental perspective. Industrial and commercial training, 36(7), 275-281.

Fredrickson, B. L. (2001). The role of positive emotions in positive psychology: The broaden-and-build theory of positive emotions. American Psychologist, 56(3), 218-226.

Fredrickson, B. L. (2009). Positivity. New York: Crown

Fredrickson, B. L., \& Branigan, C. (2005). Positive emotions broaden the scope of attention and thought- action repertoires. Cognition and Emotion, 19, 313-332.

Fredrickson, B. L., \& Joiner, T. (2002). Positive emotions trigger upward spirals towards emotional well-being. Psychological Science, 13, 172175.

Goodman, R.G. (2002) Coaching Senior Executives for Effective Business Leadership. In C. Fitzgerald and J. Garvey Berger, Executive Coaching: Practices and Perspectives. Davies- Black Publishing. Palo Alto, CA.

Grant, A. M. (2012). An integrated model of goal-focused coaching: An evidence-based framework for teaching and practice. International Coaching Psychology Review, 7(2), 146-165.

Grant, A. M. (2012). Australian Coaches' view on coaching supervision: A study with implications for Australian coach education, training and practice. International Journal of Evidence Based Coaching and Mentoring. 10, 17-33.

Hämäläinen, R. P., \& Saarinen, E. (2007a). Systems intelligence in leadership and everyday life. Espoo: Helsinki University of Technology, Systems Analysis Laboratory.

Hämäläinen, R. P., \& Saarinen, E. (2007b). Systems intelligent leadership. In R. P. Hämäläinen \& E. Saarinen (Eds.), Systems intelligence in 
leadership and everyday life. Espoo: Helsinki University of Technology, Systems Analysis Laboratory.

Hawkins, P., \& Shohet, R., (2006). Supervision in the Helping Professions $\left(3^{\text {rd }}\right.$ ed.) Maidenhead: Open University Press.

Hodge, A. (2016) The value of coaching supervision as a development process: Contribution to continued professional and personal wellbeing for executive coaches. International Journal of Evidence Based Coaching and Mentoring 14(2), 87-106

Inskipp, F. \& Proctor, B. (1993). The Art, Craft and Tasks of Counselling Supervision. Part 1: Making the Most of Supervision. Cascade: Twinkenham.

Isaacs, W. (1999). Dialogue: The art of thinking together. New York: Doubleday.

Jackson, P. \& Bachkirova, T. (2019) The 3 Ps of supervision and coaching. In Turner, E. \& Palmer, S. (Eds.) The Heart of Coaching Supervision. Routledge: New York, NY.

Kabat-Zinn, J. (1990). Full catastrophe living: Using the wisdom of your body and mind to face stress, pain, and illness. New York: Delacorte.

Kabat-Zinn, J. (1994). Wherever you go, there you are: Mindfulness meditation in everyday life. New York: Hyperion.

Kabat-Zinn, J. (2003). Mindfulness-based interventions in context: Past, present and future. Clinical Psychology: Science and Practice, 10(2), 144-156.

Kabat-Zinn, J. (2006). Mindfulness for Beginners. Boulder, CO: Sounds True.

Kabat-Zinn, J. (2008). Full Catastrophe Living - Using the Wisdom of your Body and Mind to Face Stress, Pain, and Illness. New York: Random House.

Kegan, R. (1982). The evolving self: Problem and process in human development. Cambridge: Harvard University Press.

Kegan, R. (1994). In over our heads: The mental demands of modern life. Harvard: Harvard University Press.

Kegan, R., \& Lahey, L. (2001). How the way we talk can change the way we work: Seven languages for transformation. San Francisco, CA: JosseyBass.

Kemp, T. (2008). Coach Self-Management: The Foundation of Coaching Effectiveness. In The Philosophy and Practice of Coaching. D. B. Drake, D. Brennan, and K. Gortz. 27-50

Lahey, L., Souvaine, E., Kegan, R., Goodman, R., \& Felix, S. (1988). A guide to the Subject-Object Interview: Its Administration and Interpretation. Cambridge MA: Harvard University, Graduate School of Education, Laboratory of Human Development. 
Lane, D. (2011). Ethics and professional standards in supervision . In T. Bachkirova, P. Jackson, \& D. Clutterbuck. (Eds.), Coaching and mentoring supervision. Maidenhead: Open University Press.

Laske, O. (2007). Contributions of evidence-based developmental coaching to coaching psychology and practice. International Coaching Psychology Review, 2(2), 202-212.

Lawrence, P. (2016). Coaching and adult development. In Bachkirova, T., Spence, G. \& Drake, D.B. (Eds.) The SAGE Handbook of Coaching. SAGE: Los Angeles, CA.

Lawrence, P., \& Moore, A. (2019) Coaching in Three Dimensions. New York: Routledge.

Lichtenstein, B. B, Uhl-Bien, M. Marion, R. Seers, A. Orton, J. \& D. Schreiber, C. (2007). Complexity leadership theory: an interactive perspective on leading in complex adaptive systems. In J.K. Hazy, J.A. Goldstein., \& B.B. Lichtenstein. Complex Systems Leadership Theory: New Perspectives from Complexity Science on Social and Organisational Effectiveness. ISCE Pub. Mansfield, MA.

Luoma, J. (2009). Systems intelligence in the process of systems thinking. Master of Science in Technology, Faculty of Information and Natuural Sciences, Helsinki University of Technology.

Luoma, J., Hämäläinen, R. P., \& Saarinen, E. (2008). Perspectives on team dynamics: meta learning and systems intelligence. Systems Research and Behavioural Science, 25(6), 757-767.

O'Connor, S.A., Studholme, I., \& Grant, A. M. (2017) Group coaching in a large complex organization: Lessons learnt from experience. International Journal of Evidence Based Coaching and Mentoring, 15(2), 1-16.

Passmore, J. (2007). The role of mindfulness in coaching. The Coaching Psychologist, Vol. 3, No. 3, December 2007, 1748-1104.

Passmore, J., \& Marianetti, O. (2007). The role of mindfulness in coaching. The Coaching Psychologist. 3, 131-138.

Saarinen, E. \& Hämäläinen, R. P. (2004). Systems intelligence: Connecting engineering thinking and human sensitivity. In R. P. Hämäläinen \& E. Saarinen (Eds.), Systems intelligence - discovering a hidden competence in human action and organisational life. Espoo: Helsinki University of Technology, Systems Analysis Laboratory.

Shapiro, S.L., Carlson, L.E., Astin, J.A., \& Freedman, B. (2006). Mechanisms of Mindfulness. Journal of Clinical Psychology, 62(3), 373-386.

Siegel, D. (2007). The Mindful Brain: Reflection and attunement in the cultivation of well-being. New York: WW Norton. 
Torbert, W. R. (1991). The power of balance: Transforming self, society, and scientific inquiry. Newbury Park, CA: Sage.

Uhl-Bien, M., Marion, R., \& McKelvey, B. (2007). Complexity leadership theory: Shifting leadership from the industrial age to the knowledge era. The Leadership Quarterly, 18, 298-318.

Von Bertalanffy, L. (1968). General system theory. New York: George Braziller.

Whitmore, J. (1992) Coaching for performance: A practical guide to growing your own skills. London: Nicholas Brealey.

Wilber, K. (2000). Integral psychology: Consciousness, spirit, psychology, therapy. Boston: Shambhala Publications.

\section{Author Contact}

angela.wright@coachingedgeglobal.com

sarah.tennyson@coachingedgeglobal.com

margaret@mcleanwalshllc.com 